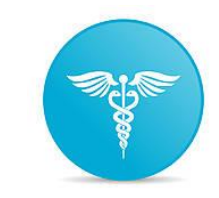

International Journal of Advances in Pharmacy and Biotechnology

Vol.3, Issue-2, 2017, 1-7

Research Article

Open Access.

I J A P B

ISSN: $2454-8375$

\title{
COMPARISON OF ANTIMICROBIAL ACTIVITY AND MIC OF BRANDED AND GENERIC FORMS OF AMOXICILLIN
}

\author{
Vasavi I*, Nagamani B, A Naga Mallika, I Indu, Aruna K, GSN Koteswara Rao, P Uma Devi \\ Viswanadha Institute of Pharmaceutical Sciences, Visakhapatnam-531173, A.P., India. \\ *Corresponding author e-mail: vasavithanvi@gmail.com
}

Received: 06 September 2017

Revised: 10 September 2017

Accepted: 15 September 2017

\begin{abstract}
:
The present work is about to determine the efficacy of different Branded and generic pharmaceuticals (antimicrobials). Branded formulations are at high cost, so that the poor can't afford to buy them. Therefore the generic drugs of various pharmaceutical companies are sold at low cost are checked for their therapeutic efficacy by comparing with that of branded for their efficacy (antimicrobial activity). Different branded and generic formulations of Amoxicillin were selected and their efficacy was tested by using cup plate method and minimum inhibitory concentration of drug that is effective towards microorganism.
\end{abstract}

Key words: Bacillus subtilis, Staphylococcus aureus, Escherichia coli, Pseudomonas aeruginosa, Branded drugs, Generic drugs and Zone of inhibition.

\section{INTRODUCTION:}

Objective: The objective of present study is to compare the antimicrobial activity of branded, generic formulations of amoxicillin and pure drug of amoxicillin on Escherichia coli, Staphylococcus aureus, Bacillus subtilis and Pseudomonas aeruginosa.

Branded vs Generics: The difference between a brand-name product and a generic one is designed to be transparent. Once the patent life expires on a brand-name drug product, it is eligible to be made into a "generic drug." To do this, the generic drug manufacturer must ensure that the drug they are producing contains the same active ingredient(s) as the brand-name product, in the same dosage form, at the same dose or concentration, and for the same route of administration (for example, amoxicillin 500 milligram (oral) capsule). The drug may differ in color, shape, taste, inactive ingredients, preservatives and packaging, however.

www.ijapbjournal.com
Because of these differences, the generic drug manufacturers are required to submit additional paperwork to the FDA to prove that their product is manufactured in accordance with good manufacturing practices (GMPs), and is as pure and stable as the branded product. Additionally, the generic needs to meet pharmacokinetic parameters in the body, which means it must dissolve (in a beaker) at the same rate and to the same extent as the original. This process ensures that the two products are bioequivalent because if product $A$ and product $B$ dissolve in a virtually identical manner, then they should behave the same in the body.

Amoxicillin is an antibiotic belongs to penicillin group of drugs useful for the treatment of a number of bacterial infections. It is the first line treatment for middle ear infections. It may also be used for strep throat, pneumonia, skin infections, and urinary tract infections among others. ${ }^{[2]}$ It is

IJAPB 
taken by mouth, or less commonly by injection.<smiles>CC1(C)S[C@@H]2C(=O)[C@@H](C2NNC(=O)[C@@H](N)c2ccc(O)cc2)N1C(=O)O</smiles>

Fig. 1: Structure of Amoxicillin

\section{MATERIALS AND METHODS}

The branded forms of amoxicillin drugs such as Almox, Novamox, Acmox, Actimox, Amoxipen and Benimox (250mg) and Generic drugs such as Labmox, Merimox, Trimox, Amx-500, Novamax and Cipmax were used for the study. The activities of these formulation were compared with pure amoxicillin procured from Arrow chemicals. Four different isolates were selected for the study. Two gram positive and two gram negative organisms. The efficacy of the antibiotics was tested using cup plate $[3,4,5]$ method and for minimum inhibitory concentration - dilution test method.24 hrs old cultures of the organisms were used for the study. The isolates were maintained by sub culturing on nutrient agar slants.
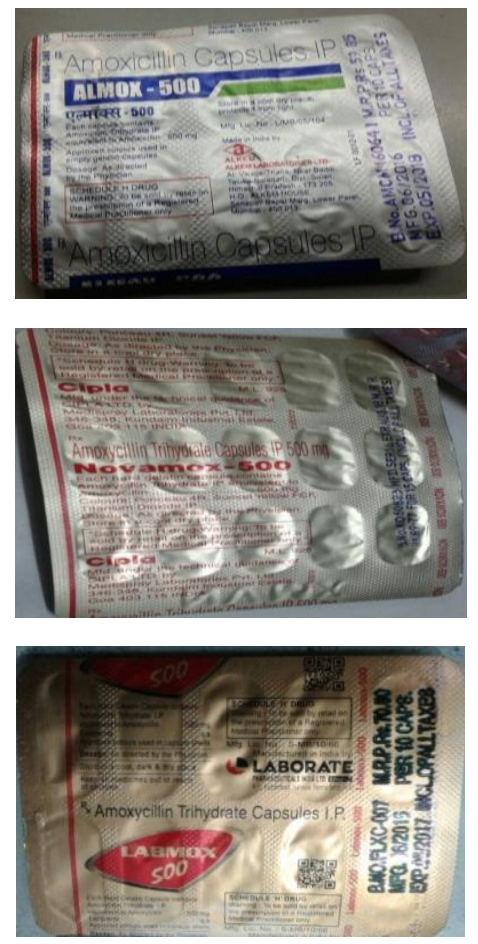

www.ijapbjournal.com
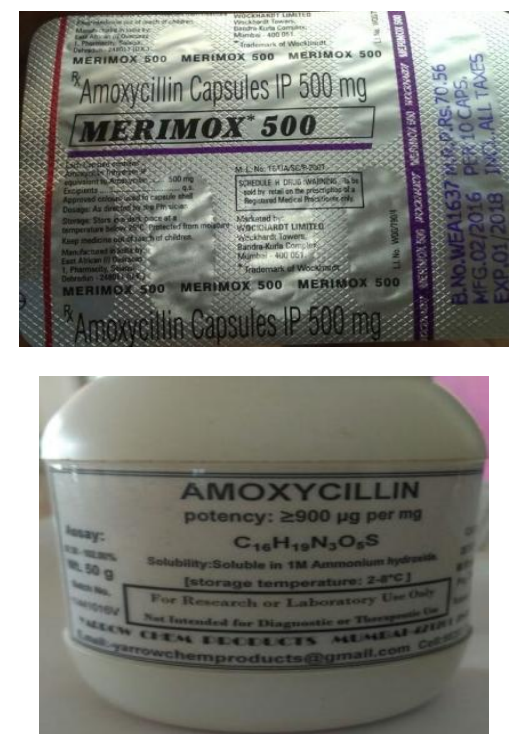

Fig. 2: Different branded \& generic products and pure drug of amoxicillin:

2a-ALMOX-500; 2b-NOVAMOX-500; 2cLABMOX-500; 2d-MERIMOX-500; 2e-Pure drug.

\subsection{Preparation of drug sample dilutions}

Tablets were powdered and 50mg of powder (equivalent to $50 \mathrm{mg}$ of drug) of each drug (pure, branded and generic drugs) was dissolved in $10 \mathrm{ml}$ of methanol that represents S1-5 mg drug in $1 \mathrm{ml}$ of methanol. $\mathrm{S} 2$ dilution (2.5 $\mathrm{mg}$ ) was prepared by adding $1 \mathrm{ml}$ of S1 drug and $1 \mathrm{ml}$ of methanol to S2 tube. S3dilution (1.25 $\mathrm{mg}$ ) was prepared by adding $1 \mathrm{ml}$ of $\mathrm{S} 2 \mathrm{drug}$ and $1 \mathrm{ml}$ of methanol to S3 tube. Thus 3 dilutions (S1, S2, and S3) were prepared. Methanol is used as control for the assay.

\subsection{Assay- cup plate method[6]}

$50 \mu \mathrm{L}$ of freshly prepared cell suspension (required organism) was inoculated into freshly prepared and sterilized nutrient agar medium by maintaining optimum temperature and transferred to sterile petri dishes and allowed them to solidify. The dishes or plates were placed on a smooth surface to ensure that the layers of medium are uniform in thickness. Cavities or cups 
were made using stainless steel borer and labeled them properly. Three different concentrations of drug (pure drug, branded and generic formulation) and controlMethanol was placed in the cavities, and allowed the petri plates for diffusion at room temperature for a period of 1 to $4 \mathrm{hrs}$. The plates were incubated at $37^{\circ} \mathrm{C}$ for a period of $24 \mathrm{hrs}$. The diameter of zone of inhibition was measured using zone reader.

\subsection{Minimum Inhibitory Concentration (MIC)}

The minimum inhibitory concentration ${ }^{[7-9]}$ is the lowest concentration of an antibiotic that prevents visible growth of a bacterium (in other words, at which it has bacteriostatic activity), whereas the minimum bactericidal concentration (MBC) is the concentration that results in microbial death (In other words, the concentration at which it is bactericidal). For determination of minimum inhibitory concentration, dilution test method is used. It involves culturing specific bacterial species in a liquid nutrient broth media into which stainless steel cylinders are dipped and then dried. The dried cylinders are then immersed in antibiotic solution under test for about $10 \mathrm{~min}$. The cylinders are then transferred to sterile culture medium and incubated for two days. The concentration of antibiotic (amoxicillin) that kills the organisms effectively was determined[10].

\subsection{Preparation of sample dilutions}

Seven different dilutions (1250, 625, 312, $156,78,39,19 \mu \mathrm{g} / \mathrm{ml}$ ) of each antibiotic were prepared for conducting MIC. $40 \mu \mathrm{l}$ of respective dilution of each drug was added to respective test tubes and kept in an incubator at $37^{\circ} \mathrm{C}$ for a period of two days. The concentration of an antibiotic (amoxicillin) that kills the organisms effectively was determined.

\section{RESULTS AND DISCUSSION}

The antimicrobial activity of amoxicillin of branded, generic and pure drug was not observed at $5 \mathrm{mg} / \mathrm{ml}$ for Bacillus subtilis and Pseudomonas aeruginosa. Zone of inhibition was observed at $5 \mathrm{mg} / \mathrm{ml}$ for Escherichia coli and Staphylococcus aureus. The antimicrobial activity of branded drugs was similar to that of that of generic drugs.

The effect of branded, generic and pure Amoxicillin antibiotic on different organisms were represented in the fig:5. All the formulations of branded, generic and pure drug of amoxicillin doesn't have noticeable effect on gram positive organisms.

\subsection{Minimum inhibitory concentration determination:}

In order to conduct minimum inhibitory concentration, seven different dilutions $(1250,625,312,156,78,39,19 \mu \mathrm{g} / \mathrm{ml})$ of all antibiotics were prepared.

MIC of amoxicillin results shown that Almox of branded formulation has got MIC value at $625 \mu \mathrm{g} / \mathrm{ml}$ for both gram negative organisms, where as remaining branded, generic formulations and pure drug has MIC value of $1250 \mu \mathrm{g} / \mathrm{ml}$. Pure drug also has similar activity as that of generics and branded forms. 
Table 1: Diameter of zone of inhibition of branded products and pure drug

\begin{tabular}{ccccc}
\hline \multirow{2}{*}{ Organism } & \multirow{2}{*}{ Drug } & \multicolumn{3}{c}{ Diameter of zone of inhibition (cm) } \\
\cline { 3 - 5 } & & S1-5 mg & S2-2.5 mg & S3-1.25 mg \\
\hline \multirow{5}{*}{ Escherichia coli } & Almox & 2.1 & 1.7 & 1.2 \\
& Novamox, & 2.0 & 1.6 & 1.0 \\
& Acmox, & 2.0 & 1.8 & 1.4 \\
& Actimox, & 1.9 & 1.5 & 1.1 \\
& Amoxipen & 2.1 & 1.8 & 1.5 \\
& Benimox & 2.0 & 1.5 & 1.1 \\
& Pure drug & 2.1 & 1.7 & 1.5 \\
& Almox & 2.1 & 1.7 & 1.5 \\
Staphylococcus & Novamox, & 2.0 & 1.6 & 1.3 \\
& Acmox, & 1.8 & 1.5 & 1.1 \\
& Actimox, & 1.9 & 1.6 & 1.4 \\
& Amoxipen & 1.8 & 1.7 & 1.1 \\
& Benimox & 2.0 & 1.6 & 1.0 \\
& Pure drug & 2.0 & 1.7 & 1.3
\end{tabular}

Note: All branded forms exhibit similar activity against microorganisms

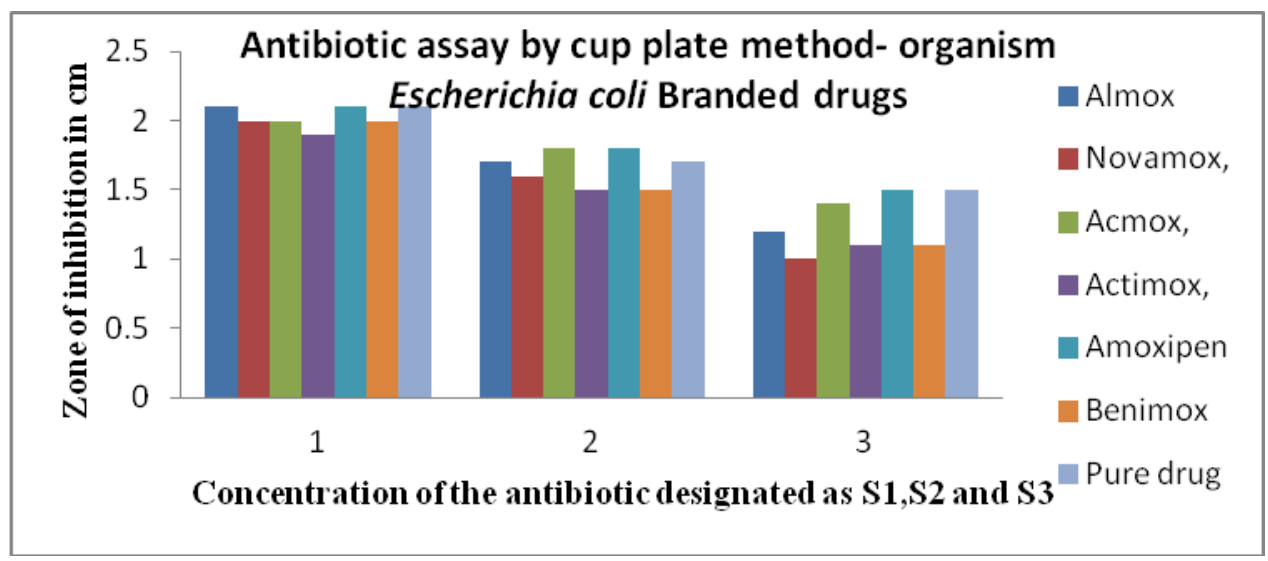

Fig. 3: Antibiotic assay of branded drugs using cup plate method. Test organism- E. coli

Table 2: Diameter of zone of inhibition of generic products and pure drug

\begin{tabular}{ccccc}
\hline \multirow{2}{*}{ Organism } & \multirow{2}{*}{ Drug } & \multicolumn{3}{c}{ Diameter of zone of inhibition (cm) } \\
\cline { 3 - 5 } & Labmox & 2.0 & 1.6 & 1.1 \\
& Merimox & 1.9 & 1.5 & 1.0 \\
& Trimox, & 1.9 & 1.4 & 1.2 \\
Escherichia coli & Amx-500 & 2.0 & 1.5 & 1.1 \\
& Novamax & 1.9 & 1.6 & 1.3 \\
& Cipmax & 1.8 & 1.7 & 1.3 \\
& Pure drug & 2.0 & 1.8 & 1.6 \\
\hline
\end{tabular}




\begin{tabular}{ccccc}
\hline & Labmox, & 2.1 & 1.8 & 1.4 \\
& Merimox & 2.0 & 1.9 & 1.6 \\
Staphylococcus & Trimox, & 2.2 & 1.8 & 1.5 \\
aureus & Amx-500 & 1.9 & 1.7 & 1.2 \\
& Novamax & 1.9 & 1.6 & 1.3 \\
& Cipmax & 1.8 & 1.6 & 1.3 \\
& Pure drug & 2.1 & 1.9 & 1.5 \\
\hline
\end{tabular}

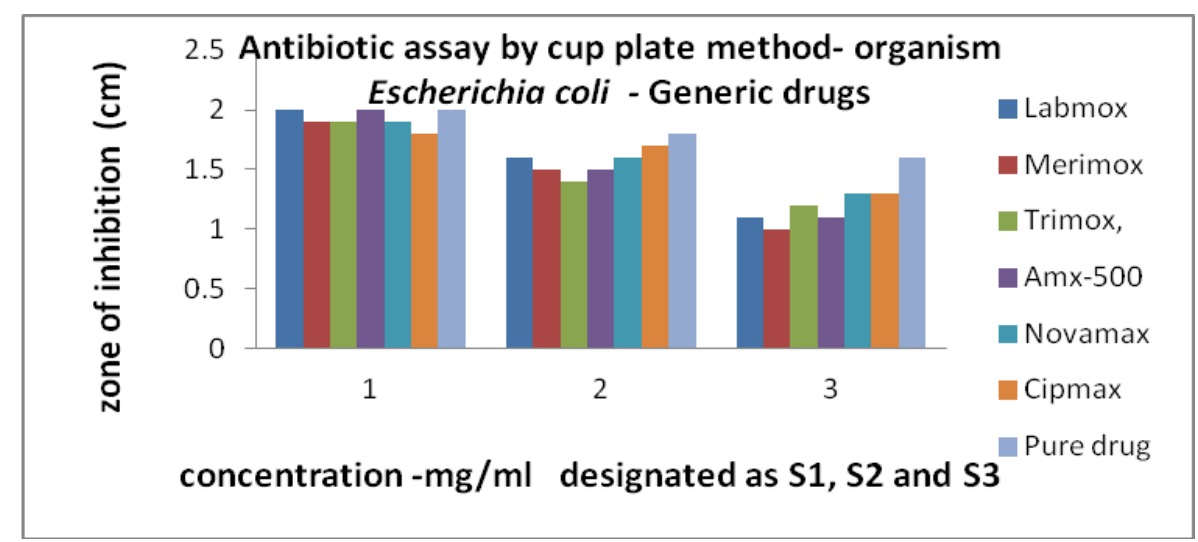

Fig. 4: Antibiotic assay of generic drugs using cup plate method. Test organism- E. coli
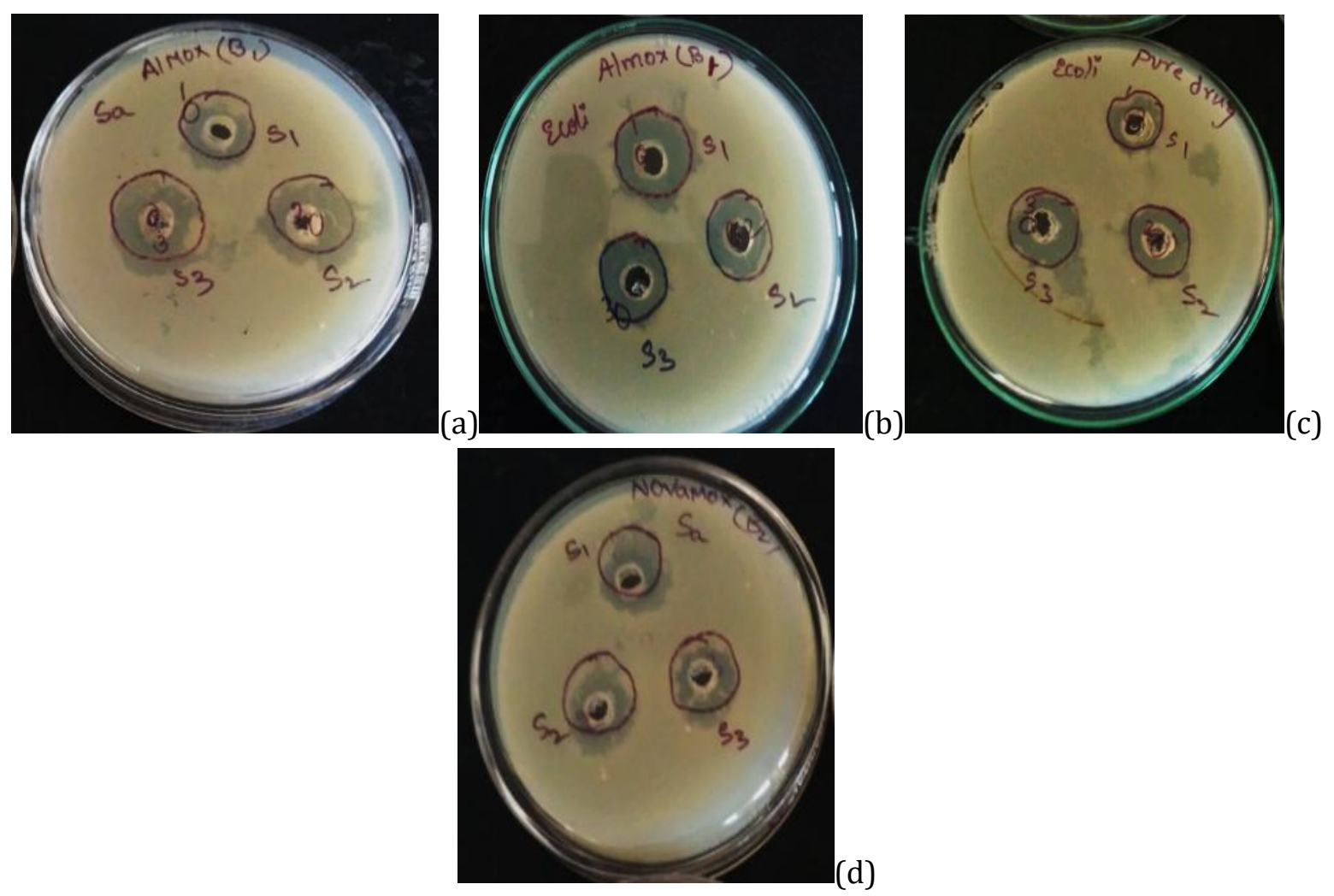

(d)

Fig. 5: Antibiotic assay of branded and generic formulations of amoxicillin-cup plate method 5(a)-Effect of Almox (branded) on S. aureus; 5(b)-Effect of Almox (branded) on E. coli; 5(c)-Effect of pure drug on E. coli and 5(d)-Effect of Novamox (generics) on S. aureus 
Table 3: MIC of different branded, generic formulations of amoxicillin and pure drug of amoxicillin

\begin{tabular}{|c|c|c|}
\hline Organism & Drug & $\begin{array}{l}\text { Minimum inhibitory concentration } \\
(\mu \mathrm{g} / \mathrm{ml})\end{array}$ \\
\hline \multicolumn{3}{|c|}{ Branded formulations } \\
\hline \multirow{7}{*}{ Escherichia coli } & Almox & 625 \\
\hline & Novamox, & 1250 \\
\hline & Acmox, & 1250 \\
\hline & Actimox, & 1250 \\
\hline & Amoxipen & 1250 \\
\hline & Benimox & 1250 \\
\hline & Pure drug & 1250 \\
\hline \multirow{7}{*}{$\begin{array}{l}\text { Staphylococcus } \\
\text { aureus }\end{array}$} & Almox & 625 \\
\hline & Novamox, & 1250 \\
\hline & Acmox, & 1250 \\
\hline & Actimox, & 1250 \\
\hline & Amoxipen & 1250 \\
\hline & Benimox & 1250 \\
\hline & Pure drug & 1250 \\
\hline \multicolumn{3}{|c|}{ Generic formulations } \\
\hline \multirow{7}{*}{ Escherichia coli } & Labmox & 1250 \\
\hline & Merimox & 1250 \\
\hline & Trimox, & 1250 \\
\hline & Amx-500 & 1250 \\
\hline & Novamax & 1250 \\
\hline & Cipmax & 1250 \\
\hline & Pure drug & 1250 \\
\hline \multirow{6}{*}{$\begin{array}{l}\text { Staphylococcus } \\
\text { aureus }\end{array}$} & Labmox & 1250 \\
\hline & Merimox & $\begin{array}{l}1250 \\
1250\end{array}$ \\
\hline & Trimox, & $\begin{array}{l}1250 \\
1250\end{array}$ \\
\hline & Amx-500 & 1250 \\
\hline & Novamax & $\begin{array}{l}1250 \\
1250\end{array}$ \\
\hline & $\begin{array}{c}\text { Cipmax } \\
\text { Pure drug }\end{array}$ & 1250 \\
\hline
\end{tabular}

\section{CONCLUSION}

From the above results, we had concluded that generic drugs showed same amount of activity as that of branded drugs as it was proved microbiologically.

So as a pharmacist we preferred generic drugs than branded forms as they are cost effective and equally active as branded ones.

\section{ACKNOWLEDGEMENT}

Authors are very much thankful to the management of Viswanadha for their support to carry out the work and providing us the required materials.

\section{REFERENCES}

[1] www.scientificamerican.com

[2] www.drugbank.ca/drugs/DB01060

[3] Nilesh Sovasia, ArshadHala, microbiological assay of antibiotics. Indian Pharmacopoeia, 2007, 45. 
[4] Ketut AdnyanaAdnyana, S. Murtini I.G.A.A.K. Wardani, Evaluation of antibacterial activity and determination of amoxicillin concentration on generic and branded products. International Journal of Pharmacy and Pharmaceutical Sciences, 2013, 5(3); 353357 .

[5] Priyanka Pathakand ,JayshreeDawane, In vitro Comparison of Generic and Branded Preparations of Amoxicillin with Potassium Clavulanate. Journal of clinical and diagnostic Research, 2016, 10(9).

[6] R. Belmar-Liberato, A. Gonzalez-Cang , P. Tamame-Martin, M. Escribano-Salazar Amoxicillin and amoxicillin-clavulanic acid resistance in veterinary medicine - the situation in Europe. A reviewVeterinarni Medicina, 2011, 56, (10); 473-485

[7] Shahhet, D. Alraghban, D. Chehna. M, Improvements of the physicochemical properties of amoxicillin trihydrate powder by recrystallization different $\mathrm{pH}$ values. International Journal of Pharmacy and Pharmaceutical Sciences, 2011, 3.

[8] K. Adnyana, S. Murtini, A. Roni, I. G. A. A. K. Wardani, Evaluation of antibacterial activity and determination of amoxicillin concentration of generic and branded products. International Journal of Pharmacy and Pharmaceutical Sciences, 2013, 5 ,3.

[9] Avery GS, Brogeden RN, Speight, TM Amoxicillin: A review of its antibacterial and pharmacokinietic properties and therapeutic use. Drugs, 1975, 2: 88 -140.

[10] H. Nakazawa,M.Matsuura, S. Mitsuhashi and $\mathrm{T}$ Hashimoto Combined antibacterial activity of amoxicillin with clavulanic acid against ampicillin-resistant strains. Journal List Antimicrobial agents Chemotherapy, 1980, 17(6): 908-911.

\section{How to cite this article:}

Vasavi I et al., Comparison of antimicrobial activity and mic of branded and generic forms amoxicillin. Int. J. Adv. Pharm. Biotech., 2017; 3(2): 1-7. 